\title{
¿De talleres a cuarteles? Control estatal, militarización y resistencia de los obreros en el nodo ferroviario de Junín, provincia de Buenos Aires (1958-1959)
}

\author{
From workshops to barracks? State control, militarization and resistance of the \\ workers in the Junín railway node, province of Buenos Aires (1958-1959)
}

\author{
María Eugenia Marengo \\ marengoeugenia@gmail.com \\ Universidad Nacional de La Plata, Argentina
}

Recepción: 06 Enero 2020

Aprobación: 20 Mayo 2020

Publicación: 01 Junio 2021

Cita sugerida: Marengo, M. E. (2021). ¿De talleres a cuarteles? Control estatal, militarización y resistencia de los obreros en el nodo ferroviario de Junín, provincia de Buenos Aires (1958-1959). Aletheia, 11(22), e090. https://doi.org/10.24215/18533701e090
Resumen: El siguiente artículo es parte de una investigación incipiente que se propone abordar las diversas formas de control policial y militar en la acción política llevada adelante por los trabajadores ferroviarios de la ciudad bonaerense de Junín, durante la gestión de Frondizi (1958-1962). Esta instancia del trabajo pretende aproximarse a las particularidades de las violencias de Estado en una escala territorial en diálogo con el contexto nacional. A partir del estudio de distintas fuentes documentales que comprenden a legajos de la Dirección de Inteligencia de la policía de la provincia de Buenos Aires (DIPPBA) y diarios locales, se intenta poner en relieve cómo fueron los mecanismos de la inteligencia provincial implementados frente a las luchas de los obreros ferroviarios de Junín.

Palabras clave: Plan Conintes, Ferroviarios, Junín, Resistencia obrera.

Abstract: The following article is part of an incipient investigation that aims to address the various forms of police and military control in the political action carried out by the railway workers of the Buenos Aires city of Junín, during the Frondizi administration (1958-1962). This instance of the work aims to approach the particularities of State violence on a territorial scale in dialogue with the national context. Based on the study of different documentary sources that include files from the Police Intelligence Directorate of the province of Buenos Aires (DIPPBA) and local newspapers, it is tried to highlight how the provincial intelligence mechanisms were implemented against the fights of the railway workers of Junín.

Keywords: Plan Conintes, Railway workers, Junín, Workers resistance. 


\section{INTRODUCCIÓN}

Este trabajo tiene por objetivo analizar las formas que tomaron las medidas de control militar a partir de la sanción de los decretos de movilización del personal que afectaron a los ferroviarios en la ciudad de Junín, provincia de Buenos Aires, durante la gestión del presidente Arturo Frondizi y el gobernador Oscar Alende (1958-1962).

La elección de un enfoque territorial busca complejizar las particularidades de las violencias de Estado. Pensar las articulaciones de las diferentes lógicas y dispositivos represivos que fueron parte de una continuidad entre gobiernos golpistas y constitucionales, cobra relevancia para comprender la represión en sus diferentes escalas territoriales. A partir de estas consideraciones, en esta aproximación a la temática se pretende brindar un panorama nacional en diálogo con el escenario local juninense.

La vida de muchos pueblos del interior estuvo, sin lugar a dudas, signada por el ferrocarril y Junín no está ajena a esta realidad. Ubicada en el noroeste de la provincia de Buenos Aires, el primer tren del ramal Ferrocarril Oeste de Buenos Aires llegó en el año 1880. Con el paso de las décadas la ciudad fue un punto de referencia obrera que concentró a miles de trabajadores en sus talleres y máquinas del tren que para el imaginario juninense fue lo que volvió grande a la ciudad (Tarullo y Iacullo, 2013).

La trascendencia de los ferrocarriles en Junín reside en que cuenta con uno de los talleres más importantes de Latinoamérica, ya que integraba una vasta cantidad de especialidades dispersas en más de cuarenta secciones. Esta característica influyó en la creciente cantidad de obreros, junto con la instalación de escuelas técnicas para el aprendizaje en los talleres. Esto se convirtió en una alerta en la mirada de la inteligencia policial que ubicaba a la localidad como un potencial centro de concentración de obreros comunistas.

El ferrocarril abre un mundo que ha vertebrado la historia del país y permite pensar su instalación como un elemento prefigurativo para analizar el Estado hasta nuestros días. Así los rieles se conectan con más de un siglo de historia que ha atravesado diversas estaciones, tan significativas como para re pensar la historia del Estado. De la expansión colonial del capitalismo que incluyó a la Argentina, "contradictoriamente en el ciclo de la expansión-explotación productiva dirigida hacia los países centrales..." (Rozintchner, González, Sorín, 2010, p. 9), hasta la desaparición de cientos de pueblos. Desde las masivas resistencias obreras, la conformación de importantes sindicatos, La Fraternidad (1887), Unión Ferroviaria (1922), hasta la traición política de sindicalistas y políticos y las luchas vigentes por el retorno del tren. Desde la reactivación de talleres en cooperativas de reparación de máquinas, hasta la creación de centros culturales dentro de las inmensas estructuras vacías y desguazadas en tantos lugares.

Ante las diversas posibilidades que se presentan para pensar el ferrocarril y su relación con el Estado, en este artículo se trabajará con los informes de inteligencia policial del Estado provincial frente a las luchas de los obreros del riel en Junín. A las distintas narrativas presentadas desde los documentos se incorporará el relato de dos ex ferroviarios que vivieron los acontecimientos acaecidos en el período. Esta aproximación a los testimonios por fuera de las categorizaciones policiales, pretende comenzar a poner en juego aquellos sentidos policiales que construyeron los expedientes bajo sus propias categorías de verdad.

En los apartados siguientes el relato contempla un abordaje a las políticas de Estado llevadas a cabo durante los dos primeros años de la gestión de Frondizi. El análisis del contexto político general permite comprender la articulación de las diferentes medidas entre la provincia de Buenos Aires y la Nación. Por lo tanto, se abordarán principalmente los aspectos de la política nacional en materia de seguridad, para luego analizar sus repercusiones en dicha localidad bonaerense ante las medidas que fueron adoptadas para el conflicto ferroviario local. 


\section{CONTEXTO POLÍTICO NACIONAL Y BONAERENSE}

Luego del Golpe de Estado que depuso al presidente Juan Domingo Perón, las Fuerzas Armadas, bajo la llamada "Revolución Libertadora", reforzaron en materia de seguridad las políticas tendientes a la creación de dependencias policiales conducidas por el poder militar, cuya finalidad exclusiva fue el acopio y la generación de información de carácter político-social.

Frente a un contexto internacional de Guerra Fría, el país, al mando de las Fuerzas Armadas, ubicó la mira en los sectores comunistas, junto con el objetivo de desperonizar la Argentina. ${ }^{1}$ La puesta en escena de un esquema represivo apuntaba hacia todo lo considerado "subversivo", donde la "amenaza comunista" fue reforzada bajo la influencia del paradigma internacional-occidental, conocido como la Doctrina de Seguridad Nacional (DSN), ineludible para las apreciaciones de las fuerzas militares y policiales de nuestro país. Este momento de consolidación internacional de la construcción de un enemigo comunista se convirtió no sólo en un mecanismo de control y represión, sino en un mecanismo de control social preventivo a través de la prefiguración y la construcción misma de la identidad comunista desde la Doctrina de seguridad nacional de los Estados Unidos. Estos factores fueron apuntando en el esquema interpretativo de las fuerzas de seguridad a una redefinición del enemigo que incorporaba la situación política nacional e internacional.

El triunfo de la Unión Cívica Radical Intransigente en las elecciones de 1958 convirtió a Arturo Frondizi en presidente y a Oscar Alende en gobernador bonaerense. La figura presidencial opositora a las medidas que representaron al gobierno militar de la Libertadora, acercó en un principio el apoyo de un amplio espectro electoral que involucró nacionalistas, católicos, ex peronistas y hasta miembros del Partido Comunista (Potash, 1985, p. 353). El acuerdo que éste mantuvo con el propio Perón desde el exilio, a cambio de levantar las proscripciones, incidió en la sumatoria de votos que lo definieron como ganador en las elecciones del 23 de febrero de 1958.

Sin embargo, la continuidad de una política proscriptiva y represiva fue parte de un escenario social que comenzaba a reunir diversas fuerzas del campo popular y la izquierda en oposición al gobierno. La conflictividad social también devino en la sanción de una serie de disposiciones que apuntaron al control del comunismo, a pesar del moderado apoyo que el Partido había manifestado al principio de la gestión. La sanción de medidas represivas fue determinante de las diversas formas institucionales que tomó la represión, siendo el Plan de Conmoción Interior del Estado (Plan Conintes) su máxima expresión durante el período indicado.

La implementación del Plan Conintes tuvo una incidencia fundamental en la militarización de la seguridad interna en nuestro país (Pontoriero, 2015), donde la centralidad en la persecución al movimiento obrero se encontró bajo una legitimidad también fundada en la justicia militar (Chiarini y Portugheis, 2014). Por otra parte, la sanción de decretos y leyes en la gestión de Frondizi pusieron en funcionamiento una maquinaria en el orden burocrático represivo en connivencia con todas las fuerzas de seguridad y defensa (Fayó, 2007).

La represión estatal y sus mecanismos de disciplinamiento se activaron de inmediato ante las resistencias que amanecían en los principales centros industriales del país. Trabajadores y trabajadoras de diversas ramas de la industria y servicios fueron afectados por los decretos de movilización del personal que declaraban como zonas militares a las ciudades que fueron epicentros de conflictos entre los años 1958 y 1962, como los protagonizados por ferroviarios y petroleros. Las huelgas se ramificaron como forma de protesta en gran parte del país, mientras que el control del espacio bonaerense fue directamente proporcional a las zonas de mayor concentración obrera donde los intereses del capital se veían perjudicados.

El conflicto con el sector ferroviario ${ }^{2}$ tuvo dos momentos clave durante el período frondicista: el comienzo de las intervenciones militares en 1958, "cuando los talleres y depósitos se transformaron en calabozos, se dormía dentro de vagones y se hacía instrucción militar” (Cena, 2010, p. 282) y la huelga general del año 1961 contra el anunciado Plan Larkin, primer intento del cierre de ramales y despidos en beneficio del transporte automotor. 


\section{LAS Formas de la Violencia de Estado en el gobierno de Frondizi}

Las diferentes medidas adoptadas en materia de seguridad interna durante la gestión del gobierno de Frondizi marcaron un significativo antecedente en la instalación de lógicas y mecanismos represivos que se fueron trazando a lo largo del resto del siglo XX. En este sentido, interesa destacar un análisis que se corre de las interpretaciones que ubican de manera dicotómica, dictadura-democracia, para pensar de qué manera los gobiernos democráticos también "fueron protagonistas y responsables" de la instalación de importantes políticas represivas (Franco, 2012).

El contexto nacional en el que asume la presidencia Arturo Frondizi se vio caracterizado por la puesta en práctica de elecciones democráticas restringidas, ya que el peronismo se encontraba proscripto. Su política estuvo determinada por un esfuerzo permanente en mantener un equilibrio hacia el interior de las Fuerzas Armadas.

Algunas de las medidas que se efectivizaron de inmediato fueron el aumento salarial del 60\%, la amnistía a los presos políticos y el levantamiento parcial de proscripciones, de las que quedaron afuera el propio Perón y el Partido. ${ }^{3}$ En agosto de 1958 se sancionó la Ley No 14.455, que establecía el régimen legal de las asociaciones profesionales de trabajadores. Esta ley permitía la creación libre de sindicatos y el reconocimiento del delegado en tanto representante gremial del lugar de trabajo, quien no podía ser despedido. Por otro lado, sus políticas apuntaron a un "desarrollismo económico" vinculado al fomento de la industria y las inversiones extranjeras, habilitando a éstas a través de un marco legislativo. ${ }^{4}$

Estas medidas y las políticas de estabilización ante la crisis económica que se comenzó a sentir hacia fines de 1958, dieron un giro en el carácter inicial del gobierno cuando se aplicaron políticas de ajustes con préstamos del Fondo Monetario Internacional (FMI), congelamiento salarial y devaluación. Junto a estas disposiciones se extendieron las huelgas y las medidas represivas se intensificaron. Los sindicatos se manifestaron con planes de lucha y la represión a cargo del Ejército recrudeció. En este contexto, el 14 de noviembre de 1958, bajo el Decreto de carácter secreto No 9.880, se aprobó el llamado Plan de Conmoción Interna del Estado (Plan Conintes), que prohibía las huelgas, permitía la intervención de las Fuerzas Armadas y los detenidos acusados por el delito de "terrorismo" quedaban bajo la competencia de tribunales militares.

Como normativa de excepción, el Plan Conintes facultaba la militarización de la sociedad al declarar zonas de injerencia militar, principalmente a las ciudades industriales, limitando los derechos y garantías constitucionales de las personas.

El Poder Ejecutivo fundamentaba la sanción del decreto al reconocer la existencia de un estado de perturbación social que afectaba y ponía en peligro las instituciones del país y el orden público, ante el cual ya se había declarado el estado de sitio, que dio lugar a las Fuerzas Armadas a proceder con autoridad para restablecer el orden. Mediante esta medida el Poder Ejecutivo se atribuía el derecho de poder de policía en todo el país y generaba la intervención militar de manera desmedida.

En los artículos $2^{\circ}$ y $3^{\circ}$ del decreto se habilitaba la intervención desde el Ejército, la Armada Nacional y la Aeronáutica Militar para resolver situaciones que fueran consideradas perturbadoras al orden público, mientras que la policía quedaba subsumida a las Fuerzas Armadas. Desde el Ministerio de Defensa Nacional, Secretaría de Guerra, Marina y Aeronáutica se debían adoptar las medidas necesarias para ejecutar el Plan de Conmoción Interna del Estado. ${ }^{5}$

Este plan de seguridad y militarización tuvo un fuerte impacto en la vida política del país, se declaró la intervención de sindicatos, se allanaron domicilios y reprimieron huelgas. El espacio público se convirtió en un lugar agresivo que excedía cualquier norma legal posible. Estas intervenciones tuvieron varios efectos, como explica Marina Franco, por un lado "conculcaron garantías constitucionales y fueron usados como instrumentos represivos legalmente respaldados y, por el otro, habilitaron un creciente espacio de autonomía militar en el control del orden interno" (Franco, 2012, p. 5). 
En efecto, la sanción del decreto Conintes daba cuenta de la existencia de un gobierno que fue prefigurando modos represivos que marcaron la excepcionalidad como una característica constituyente del Estado Moderno. La violencia institucionalizada comenzó a cumplir aquí su rol dentro de un Estado que mantuvo sus funciones de control social y represión mediante una continuidad histórica y constitutiva de la misma.

\section{LA TERRITORIALIZACIÓN DE LA REPRESIÓN: JUNÍN, ENTRE FERROVIARIOS Y MILITARES}

La subordinación de la policía a las autoridades militares, la creación posterior de los Consejos de Guerra especiales para los y las detenidas bajo la normativa del Conintes y la zonificación de la vigilancia fue construyendo una territorialización de la represión que buscaba un control político-militar constante sobre la población. La vida y el espacio comenzaban a convertirse en una dupla biopolítica y geopolítica (González Hernández, 2017), donde el control del espacio requería, a su vez, de una política sobre la vida para controlarla.

La división en zonas militares del país tiene su antecedente en el Decreto $\mathrm{N}^{\circ} 15.385$ del año 1944, por el cual se crearon las "zonas de seguridad" destinadas a fortalecer la defensa nacional que comprendían una faja a lo largo de la frontera terrestre-marítima y una cintura alrededor de aquellos establecimientos militares o civiles del interior existentes especialmente para la defensa del país. ${ }^{6}$ En Argentina no existía todavía ninguna ley que contemplara la seguridad de las zonas fronterizas, consideración que tuvo la Secretaría del Consejo de Defensa Nacional y quedó efectivizada en dicho decreto.

Durante los primeros meses de la presidencia de Frondizi se sancionaron los Decretos $\mathrm{N}^{\circ} 312$ y $\mathrm{N}^{\circ} 314$, los cuales dejaron sin efecto las intervenciones militares efectuadas por el gobierno de Aramburu a los gremios de la carne, metalúrgicos, sanidad, textiles, bancarios y transportes, y se restablecieron las direcciones elegidas por los agremiados (Chiarini y Portugheis, 2014, p. 71). A pesar de este cambio en el gobierno frondicista, pronto se implementarían las medidas de intervención militar ante los nuevos focos de huelgas y manifestaciones obreras.

A lo largo del año 1958 las demandas desde el sector ferroviario hacia el gobierno nacional fueron permanentes. En mayo, luego de la asunción de Frondizi al poder, las negociaciones entre los gremios La Fraternidad y la Unión Ferroviaria con el gobierno continuaron un camino tenso que confluyó en intervenciones militares y detenciones. El 9 de octubre hubo un llamado a paro general por tiempo indeterminado, donde entre otras cosas, se exigía el reconocimiento de la auténtica Comisión Directiva de la Unión Ferroviaria ante la intervención militar del gremio. En este caso la medida afectaba al personal de "Guarda Trenes" únicamente.

En este tire y afloje entre gremios y gobierno se llegó a la huelga del 28 de noviembre, una medida que arrastraba a todas las instancias de lucha anteriores, cuyas principales demandas fueron la exigencia de mejores condiciones de trabajo y el pago de retroactivos. La respuesta desde el Estado fue la intervención de la Unión Ferroviaria y la militarización de las estaciones y playas con personal de las tres Fuerzas Armadas y la gendarmería. Las seis líneas del ferrocarril estatal quedaron a cargo de los Jefes del Ejército y en las estaciones donde faltaba personal se recurrió a jubilados movilizados, inspectores o empleados de emergencias y "las Fuerzas Armadas se dedicaron a la vigilancia y ordenamiento del trabajo organizadas en "piquetes" en los puntos claves de las estaciones" (Fayó, 2007, p. 12).

Luego del 28 de noviembre, una vez más, las actividades gremiales fueron suspendidas y se decretó la movilización del personal ferroviario que quedó bajo la disposición del Código de Justicia Militar. En diciembre en algunas estaciones de los ferrocarriles Belgrano y San Martín se podían encontrar guardas rapados, formados en los andenes bajo las órdenes de oficiales y suboficiales del Ejército que les daban voces de mando, mientras eran acompañados para reanudar sus tareas por soldados. ${ }^{8}$ 
El Plan Conintes ya estaba en marcha, a partir de aquí la realidad intervencionista desde el orden de lo militar y policial se convertiría en una lamentable postal que transformaría el paisaje urbano de muchas localidades bonaerenses.

Desde las estructuras policiales de la inteligencia bonaerense se distinguía a la provincia de Buenos Aires como la zona donde se concentraban las principales fuerzas del comunismo argentino 9 y Junín era detectada como un área de influencia comunista ante la importancia de los talleres ferroviarios que para estos años ya concentraba a miles de trabajadores.

En la búsqueda de operatividad policial se activaron las Unidades Regionales (UR) que fueron parte de la estructura del funcionamiento de la inteligencia policial bonaerense, creadas durante peronismo. La sede central de la inteligencia estaba en La Plata, pero funcionaba de manera articulada con las distintas delegaciones de inteligencia que se encontraban en las cabeceras de cada una de las Unidades Regionales de la provincia. ${ }^{10}$

Organigrama de funcionamiento de la Central de Inteligencia bonaerense, 1957 (Archivo DIPPBA, Mesa Doctrina ${ }^{11}$ )

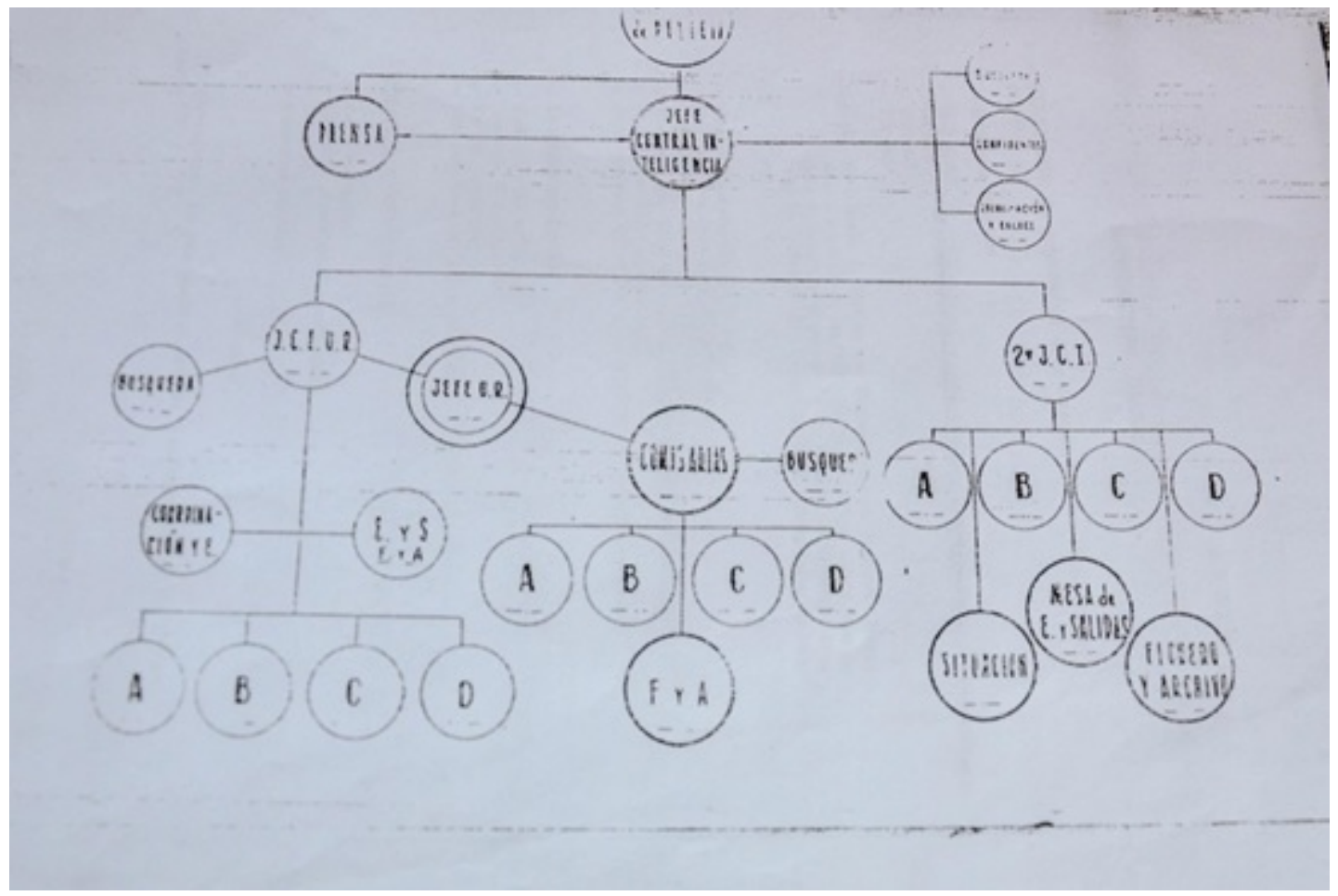

Como puede verse, la Delegaciones Regionales se conectaban con las comisarías y tenían como objetivo recaudar toda la información propia de la Central en el radio jurisdiccional. Las letras correspondían a los distintos departamentos temáticos donde se clasificaba luego la información: Registro de Partidos Políticos, Entidades Estudiantiles, Prensa, Comunal, Gremial, Fabril, Entidades de bien público, religiosas, etc.

Junín se constituía como la Unidad Regional V y centralizaba la información de Carlos Casares, Chacabuco, Chivilcoy, General Arenales, General Pinto, General Viamonte, General Villegas, Lincoln, 9 de Julio, Pehuajó, Rivadavia, Trenque Lauquén. Aunque, según los legajos en aquellas localidades que no eran asiento de Unidades Regionales, el jefe de las distintas comisarías locales designaba un oficial que ejercía como subdelegado de la Central de Inteligencia.

Hacia el año 1959 la situación de los obreros del riel no había cambiado. Los conflictos se agudizaban y los paros continuaban. El rechazo a la intervención militar generó a mediados del mes de mayo un paro general convocado desde los gremios de la Unión Ferroviaria y La Fraternidad, cuya adhesión en los talleres 
ferroviarios de Junín fue total. Esta situación dio origen a la detención de varios trabajadores por orden del Comando de Movilización Militar, que estaba a cargo de la intervención en el ferrocarril. Durante la noche fueron allanados domicilios en busca de dirigentes comunistas locales y siguieron durante el día, como daba cuenta la crónica periodística del diario La Verdad:

penetraron al taller del ferrocarril varios soldados armados que procedieron a detener a otros tres obreros. Ello originó una rápida reacción de los demás obreros (...) que al no lograr la libertad de los compañeros detenidos, hicieron abandono de sus tareas (...) originando una manifestación formada por unas 2000 personas que luego apareció (...) en dirección al centro de la ciudad y se ubicó frente al local del Distrito Militar 17 (Diario La Verdad Junín, 17 de mayo de 1959, Archivo Histórico de la ciudad de Junín)

Era la primera manifestación popular en la ciudad con estas características. El apoyo a los ferroviarios visibilizó el conflicto a través de las calles de la ciudad junto con la solidaridad de los demás gremios.

Los talleres de Junín estaban a cargo del Jefe de la Movilización, Mayor Tessas. En los legajos de la Central de Inteligencia aparecen algunos sucesos de estos conflictos, particularmente con la detención de uno de los obreros de la sección de tornería, quien al negarse a ser llevado por soldados expresó: "si el Mayor Tessa desea conversar conmigo, que venga al taller”. De inmediato los compañeros del trabajador rodearon a la Comisión Militar que pretendía llevarlo, hasta lograr, luego de un forcejeo, que se fugara. Según la información brindada por la policía ferroviaria, el resto de los obreros instó al personal a que se manifestaran por las calles céntricas de la ciudad al grito de libertad: "Todo ello acompañado de gritos hostiles hacia el gobierno y la movilización. Un total de aproximadamente 1400 personas (en su mayoría ferroviarios) recorrieron la calle Rivadavia hasta enfrentar el distrito militar" (Archivo DIPPBA, Mesa B, 29 de mayo de 1959).

En este relato surge la policía ferroviaria constituida como informante. Esta policía era un cuerpo orgánico al ferrocarril que dependía directamente de la gerencia de los ferrocarriles. La mayoría de los ex obreros la recuerda con su guardapolvo gris, efectiva para evitar delitos relacionados con el robo de pertenencias en los trenes y talleres. Sin embargo, aquí su presencia devino en informante de la policía ${ }^{12}$ al contribuir con nombres, apellidos y filiación política de los obreros que más se referenciaron durante el conflicto, datos que fueron enviados desde la delegación Junín a la Central de Inteligencia.

Aquella entrada abrupta de soldados para detener a un obrero en los talleres es recordada por Floreal Volini, ex obrero ferroviario, quien como delegado de la Unión Ferroviaria integró la Comisión de reclamo local. Por aquel entonces tenía 27 años, "acá se llegó casi a la toma de la comisaría. Fueron a detener a cuatro compañeros en el ferrocarril, tres ya se habían llevado, fueron a buscar a Mario Andrade al taller, estaba al lado del torno. Se armó un gran lío, era sábado, salimos a la calle como tres mil y pico de obreros" ${ }^{13}$

En las calles también aparecieron las familias que se incorporaron a la manifestación. Floreal fue uno de los que medió para la resolución del conflicto que finalmente terminó con la libertad de los trabajadores detenidos. Recuerda que habló con el Coronel Blanco, Jefe del Regimiento de Junín, y que al llegar a los cuarteles había seis camiones con soldados en su interior, el Coronel al verlo llegar le dijo: "eso [en alusión a los camiones] que hay ahí es para ustedes", a lo que Volini contestó “metanlé, porque a las dos de la tarde Luz y Fuerza baja la palanca (...) Había un muchacho en la calle, uno de izquierda, con un cartel que decía Luz y Fuerza presente. Era el único que había, pero estaba bien clarito y sirvió”.

La presión obrera era palpable, al punto de ratificar el mismo comisario al Coronel la posibilidad de la acción de Luz y Fuerza. Luego de este hecho, Floreal terminó pelado y detenido durante quince días en los cuarteles: "ese era el castigo. Te llevaban al cuartel a dormir, a la mañana te levantaban para ir al trabajo y volvías al cuartel”.

El acuartelamiento de los trabajadores comenzaba a ser una posibilidad concreta durante el año 1959. La militarización de los conflictos obreros tomaba diversas aristas dentro de este contexto histórico, la disciplina militar resultaba ser la metodología ejemplificadora para evidenciar el desorden social, la desobediencia y la insubordinación a la autoridad. 
Desde el informe policial la manifestación recaía en las categorías "de corte netamente comunista", a pesar de que sólo uno de los detenidos era miembro del Partido Comunista, todo el informe se esforzaba por centralizar las responsabilidades a este enemigo común propagado por el territorio bonaerense. El conflicto continuó cuando los obreros tomaron la sede local de la Unión Ferroviaria y conformaron una comisión directiva provisoria, una "comisión de resistencia" en palabras de Floreal. Los problemas internos en el gremio habilitaron a los militares a continuar con las detenciones hacia los trabajadores. En el informe de inteligencia se expresaba que el día 25:

esta comisión provisoria de neta tendencia comunista se presentó con un abogado y un escribano para hacerse cargo del local de la Unión Ferroviaria. [...]. En el mismo se encontraban integrantes de la comisión Ejecutiva que se negaron a entregar el mismo, poniendo en conocimiento del Comando de Movilización lo que acontecía, ya que desconocían de por sí a la Comisión Provisoria que venía a hacerse cargo del local (Archivo DIPPBA, Mesa B, 29 de mayo de 1959).

Las autoridades militares continuaron con la detención de todos los integrantes de la Comisión Provisoria, que según el informe de inteligencia se identificaban con diversas tendencias políticas: comunistas, nacionalistas, UCRI, demócratas progresistas y anarquistas. Ante las detenciones el resto de los trabajadores de los talleres, que eran un total de 3.730 obreros, no fueron a trabajar. De este modo, el panorama de militarización comenzó a extenderse por fuera de los talleres ferroviarios.

El personal jerárquico de Movilización solicitó más refuerzos con la intención de que se retomara el trabajo. Así, hacia finales del mes de mayo de 1959 la ciudad quedó sitiada por cien efectivos del Regimiento 6to. de Infantería con asiento en la ciudad bonaerense de Mercedes, cien efectivos de Gendarmería Nacional y cincuenta agentes de Caballería de la Policía de la Provincia de Buenos Aires.

La situación se prolongó durante varios días, mientras que, como se describe en el informe policial, "las tropas patrullaron las calles a fin de evitar manifestaciones y disturbios" (Archivo DIPPBA, Mesa B, 29 de mayo de 1959, folio 104). La adhesión al paro fue masiva y se incorporó también el personal del Depósito de Locomotoras, Tráfico, Vías y Obras. Ante esta última situación, las autoridades militares del Comando de Movilización Ferroviaria extremaron las medidas, no permitieron el derecho a huelga y detuvieron a dieciocho ferroviarios más que fueron buscados en sus casas por la noche del 27 de mayo, "haciéndoseles saber que no se los consideraba detenidos, sino que se los incorporaba al trabajo en calidad de acuartelados" (Archivo DIPPBA, Mesa B, 29 de mayo de 1959, folio 106). Las detenciones efectuadas por la policía fueron acompañadas por el personal de Gendarmería Nacional, que respondían a las directivas de los Comandos militares de Movilización.

En 1959 Ismael Tornello tenía 17 años y trabajaba en los talleres ferroviarios de Junín. De aquella movilización recuerda cómo se subían a los árboles y tiraban naranjas en la comisaría, la cantidad de gatos que llevaban para enloquecer a los perros de la policía y la imagen de los obreros rapados como una marca de época: "con la intervención se escapaban muchos, para no ser llevados a los cuarteles". ${ }^{14}$ La situación de los "prófugos" para el Comando de Movilización dio como resultado más allanamientos nocturnos en las casas de las familias de los trabajadores. El diario local describía la actitud de los gendarmes que estaban cumpliendo tareas de vigilancia en la ciudad y "obrando bruscamente penetraron en los domicilios en que se hallan los familiares de los prófugos entregados al sueño y procedieron a revisar las dependencias sin respetar la tranquilidad de las criaturas a quienes lógicamente, tal presencia a esas horas aterroriza" (Fueron puestos en libertad los ferroviarios detenidos (17 de mayo de 1959, La Verdad).

El tono de la nota del diario local expresaba el malestar social frente a la intromisión de las fuerzas de seguridad en la vida civil juninense. Como se expresó, la ciudad tenía en esa época un fuerte arraigo en la identidad ferroviaria, más allá de las internas políticas y gremiales que subyacían al interior de los conflictos. ${ }^{15}$ La salida a las calles de los obreros, también implicaba exteriorizar el estado de movilización militar en los talleres. Esta extensión del intervencionismo militar en las casas y en el espacio público construía un panorama 
de vigilancia y control en la ciudad que disgustaba a ciertos sectores de la sociedad: comerciantes, iglesias y vecinos, como puede comprenderse desde los artículos de la prensa local.

Estas situaciones de control y represión fueron habilitando la sistematicidad de prácticas de excepción. Poco a poco, las Fuerzas Armadas comenzaron a cumplir funciones de vigilancia y las instituciones policiales incorporaron a su disciplina una militarización interna para garantizar el ejercicio represivo sobre el control total de la población.

Por otro lado, esa dimensión de lo militar como parte de lo cotidiano en la sociedad civil comenzaba a construir un imaginario de lo posible. Los informes policiales insistían en que "la actitud del pueblo en general ha sido pacífica sin dar ni tomar ingerencia [error del original] alguna en el conflicto" (Archivo DIPPBA, Mesa B, 29 de mayo de 1959, folio 106). Esta interpretación que se relativiza con los testimonios y la prensa de la época, parecía una respuesta maniquea de una orden cumplida con éxito para aprobar la continuidad del intervencionismo militar como un medio de resolución de conflictos. A la luz de los informes se seguía tergiversando la dimensión de la lucha obrera y poniendo en un primer plano a una "minoría comunista aún sin el apoyo de los trabajadores [que] explota un hecho para usufructuar en beneficio del partido situaciones sicológicas gremiales" (Archivo DIPPBA, Mesa B, 29 de mayo de 1959, folio 106).

El enemigo privilegiado para los servicios de inteligencia continuaba siendo el comunismo, a pesar que entre los detenidos las filiaciones ideológicas y partidarias fueron ampliamente diversas. Estos conflictos funcionaron como motores claros del anticomunismo policial que operó durante el siglo XX como base de las agendas políticas y legitimó tanto un aparato jurídico como el afinamiento de técnicas y estructuras policiales para la represión del comunismo. Como destaca Casals, las expresiones anticomunistas "no siempre estuvieron supeditadas a la existencia 'real' de una 'amenaza' de este tipo, en la medida en que ese ímpetu opositor estuvo dado también por la defensa de una serie de valores, principios y prácticas asumidas como positivas y sostenedoras del orden social" (2016, p. 58).

Desde las primeras detenciones en mayo de 1959, los obreros de Junín fueron sometidos al juzgamiento militar: "se hace constar que los nombrados precedentemente, son juzgados por el Consejo de Guerra nro. 1 a excepción de XXXX, que se halla detenido en la Agrupación Blindada "C" con asiento en ésta ciudad cumpliendo 30 días de arresto a partir del 1ro. del corriente" (Archivo DIPPBA, Mesa B, 29 de mayo de 1959, folio 106).

Veinte trabajadores detenidos, clasificados entre comunistas y peronistas, más una nómina detallada de obreros desertores por no ir a trabajar los días de paro, fueron juzgados por un Consejo de Guerra constituido para la resolución de este conflicto. Las penas variaron entre dos y siete meses de prisión y en algunos casos treinta y cuarenta y cinco días de arresto.

La situación de los ferroviarios de Junín demuestra que tanto las detenciones, las causas sin investigación y las penas de prisión se implementaron antes del decreto $\mathrm{N}^{\circ} 2628^{16}$ que hizo público en marzo de 1960 la vigencia y la declaración de la Conmoción Interior del Estado y la aplicación del decreto $\mathrm{N}^{\circ} 2639$ del mismo año, ${ }^{17}$ que ordenaba que las personas detenidas en el marco del Conintes fueran juzgadas sumariamente por consejos de guerra militares, constituidos por los comandantes de las zonas delimitadas a nivel nacional.

La realidad que vivían los obreros ferroviarios fue denunciada desde las distintas Comisiones Coordinadoras de las seccionales del gremio Unión Ferroviaria. A pesar de las tensiones encontradas, al principio, con el gremio y un sector de los trabajadores de Junín, hacia el mes de junio la situación devino en una clara toma de posición al respecto, donde la propia Unión Ferroviaria estaba intervenida con la prohibición de las actividades sindicales. El Servicio de Informaciones de la Provincia de Buenos Aires obtuvo copias -enviadas por la delegación Central de Inteligencia de Junín- de los volantes que desde dicho gremio hacían circular entre los trabajadores. En el mismo se denunciaba que en el sexto mes de movilización militar los obreros trabajaban "con bayonetas en la espalda, bajo la prepotencia y la brutalidad militar, como prisioneros de guerra”. Se describían los abusos efectuados por los Comandos de movilización como compañeros estaqueados en Olavarría, golpes y torturas a obreros en Campo de Mayo, un señalero muerto en 
Pehuajó, el jefe de estación Derqui herido de bala, en Bahía Blanca se prohibió a los compañeros socorrer a un accidentado, los cuerpos a tierra hasta la extenuación, fajinas, plantones, etc". A esto agregaban las condenas desde diez días hasta dos años. "No hay cuartel militar que no encierre algún compañero ferroviario ya que nuestra libertad depende del humor del Capitán de turno". (Archivo DIPPBA, Mesa B, 13 de junio de 1959, folio 26).

Esta era la situación cotidiana de muchos de los obreros que debían trabajar bajo la autoridad militar. "Se pretende hacer norma de lo arbitrario", denunciaban los trabajadores en el volante secuestrado por la DIPPBA. El gobierno quedaba fuera de la ley transformando a los obreros en soldados permanentes bajo códigos y leyes militares que hacían de la autoridad castrense un abuso constante. En tiempos de paz se aplicaban las medidas de tiempos de guerra. ${ }^{18}$

Finalmente, hacia el mes de julio el gobierno, decreto mediante, levantó la medida de movilización military firmó indultos a los trabajadores movilizados de los sectores petroleros, ferroviarios y de transporte de Buenos Aires que habían sido juzgados por tribunales militares entre el 27 de noviembre de 1958 y el 30 de junio de 1959 ("Dictóse el indulto", 1959). De esta manera, recuperaron su libertad trabajadores de la localidad de Junín, pero la situación interna en los talleres locales continuó con reclamos y demandas obreras durante el resto del año 1959. La exigencia de la reducción del horario laboral ante las condiciones de insalubridad en la secciones de herrería, locomotoras, coches y vagones y el plantel de estopa, abrirían una serie de nuevos conflictos que repercutirían en la toma de medidas de fuerza de ciento sesenta obreros de los talleres General San Martín de Junín.

\section{Consideraciones Finales}

En términos generales, puede entenderse cómo en la provincia de Buenos Aires la militarización de las zonas con mayor concentración obrera fue una medida sistemática para la resolución de conflictos durante el gobierno de Frondizi. Los decretos de movilización de personal que afectaron a sectores como el ferroviario se constituyeron en uno de los recursos más utilizados por el Estado, junto con el estado de sitio y las detenciones de civiles en manos de los Comandos de Movilización. Esto resultó ser un combo de excepcionalidad creado para contener y desestabilizar a las manifestaciones sociales, como así también prever las futuras reacciones dentro del movimiento obrero ante la avanzada del programa económico de ajuste del gobierno.

La puesta en práctica del Conintes como antecedente de la Doctrina de Seguridad Nacional, fue la contrapartida de las manifestaciones obreras y los conflictos sociales que estallaron en diversos focos de lucha a la largo del territorio nacional. Como se pudo ver con la experiencia ferroviaria, el Plan Conintes se aplicó antes de la sanción de los decretos $\mathrm{N}^{\circ} 2628$ y 2639 de 1960, que hicieron pública la vigencia de la Conmoción Interna del Estado y habilitó que las personas detenidas en el marco del Conintes fueran juzgadas sumariamente por consejos de guerra militares, respectivamente.

El estado de movilización militar como respuesta a la reacción de los trabajadores del riel ante sus demandas, generó en la ciudad una postal de época que en aquel presente no fue bien recibida. Mientas desde los informes de inteligencia se minimizaban los efectos posibles de la intervención en la población, la prensa local transmitía la incomodidad del patrullaje en la ciudad. A este último hecho se sumaba como forma de exteriorización de la intervención ferroviaria, la imagen de los obreros con las cabezas rapadas y los allanamientos nocturnos en las casas de sus familias.

Expresiones de los legajos policiales tales como "la gravitación comunista", se convertían en mecanismos legítimos para dar continuidad al control militar en la zona. La movilización militar implicó además la incorporación de la disciplina castrense en los talleres ferroviarios como una forma de organización del trabajo. Los obreros estuvieron sometidos por casi un año a un régimen que ponía también al cuerpo en el lugar del castigo. Las cabezas rapadas, como se expresó, significaron una marca de época que corporalizaba la sanción y demostraba cuáles eran aquellos cuerpos incorrectos que alteraban el orden interno. 
Se comprende que a partir de estas medidas el gobierno nacional apuntó a conciliar la legalidad con la represión. La intendencia local no tuvo injerencia en los conflictos, mientras que las manifestaciones obreras se concentraron en los lugares donde estaban las fuerzas policiales y/o militares, comisaría y Distrito Militar. Esta acción desde los trabajadores ilustraba y definía la realidad del gobierno de Frondizi, donde la sustitución del poder civil por la autoridad militar fue política de Estado y discrecionalmente fueron otorgadas facultades al Ejército por encima del Congreso de la Nación.

La lectura desde los expedientes policiales magnifica por momentos lo que surge desde la vivencia transmitida por los testimonios presentes en este artículo. Las versiones policiales configuran así una trama de la vigilancia policial que se entendía a sí misma como mucho más poderosa de lo que realmente era.

No obstante, estos expedientes abren algunas posibilidades para continuar indagando en nuevos relatos sobre el pasado histórico del ferrocarril de Junín. Como se explicó, este artículo conforma una instancia inicial que pretende comenzar a pensar el territorio como dimensión de la represión, en un contexto que permite hallar signos del anticomunismo local como ejercicio sintomático de una práctica global que buscaba cosechar convenientemente enemigos por todas las latitudes.

\section{REFERENCIAS}

Casals Araya, M. (2012). Anticomunismos, politica e ideología en Chile. La larga duración de la "Campaña del Terror" de 1964, Tesis de Maestría en Historia. Santiago de Chile: Universidad Católica de Chile.

Cena, J. C. (2010). Las Vías en la Argentina, en el $150^{\circ}$ Aniversario de su instalación. En AA. VV., Vias Argentinas, Ensayos sobre el Ferrocarril (pp. 269-294.). Buenos Aires: Milena Caserola.

Chiarini, S. y Portugheis, R. (coords.) (2014). Plan Conintes. Represión politica y sindical. Buenos Aires: Ministerio de Justicia y Derechos Humanos. Secretaría de Derechos Humanos. Archivo Nacional de la Memoria.

Cinat, N. (2010). Síntesis Histórica de los Ferrocarriles en la Argentina. AA. VV., Vias Argentinas, Ensayos sobre el Ferrocarril (pp. 107-124). Buenos Aires: Milena Caserola.

Dictóse el indulto de trabajadores sancionados por tribunales militares (21 de julio de 1959), La Verdad, portada.

Fayó, I. (2007). La institucionalización de la intervención de las Fuerzas Armadas argentinas en política interna. La ley 13234: inauguración de una nueva modalidad represiva, 1958-1961, XI Jornadas Interescuelas/Departamentos de Historia. San Miguel de Tucumán: Universidad de Tucumán.

Franco, M. (2012). Rompecabezas para armar: la seguridad interior como política de Estado en la historia argentina reciente (1958-1976), Revista Contemporánea: Historia y problemas del Siglo Veinte, 3, pp. 77-96.

Fueron puestos en libertad los ferroviarios detenidos (17 de mayo de 1959), La Verdad, portada.

González Hernández, B. (2017). La construcción bio/geopolítica de las Doctrinas de Seguridad Nacional, Cuadernos DO CIM, 1 (1), pp. 61-79.

Instituto Nacional Juan Domingo Perón de Estudios e Investigaciones Históricas Sociales y Políticas (2010). Plan Conintes y Resistencia Peronista 1955-1963. Buenos Aires.

Pontoriero, D. E. (2015). Estado de excepción y contrainsurgencia: El Plan Conintes y la militarización de la seguridad interna en la Argentina (1958-1962), Contenciosa, 4, pp. 1-16.

Portelli, A. (1991). Lo que hace diferente a la historia oral. En D. Schwarzstein (comp.), La historia oral. Buenos Aires: CEAL.

Potash, R. (1985). El ejército y la política en la Argentina (II). 1945-1962, de Perón a Frondizi. Buenos Aires: Hyspamerica.

Rapan guardas de ferrocarriles (3 de diciembre de 1958), La Verdad, portada.

Rozintchner, L., González, H. y Sorín, J. (2010). "Introducción”. En AA. VV., Vias Argentinas, Ensayos sobre el Ferrocarril. Buenos Aires: Milena Caserola, pág. 9

Tarullo, R. y Iacullo, A. (2013). Ferroviarios. Nuestra historia. Junín: UNNOBA. 


\section{Notas}

1 El término comunista será utilizado en referencia a todo lo vinculado al Partido Comunista, sus militantes y simpatizantes, como también a la categoría de enemigo interno.

2 Un análisis sobre los antecedentes de las huelgas ferroviarias durante el gobierno de Perón, puede verse en: Mengascini, H. (2018). Conflictos y huelgas ferroviarias durante el período peronista (1946-1955), 3ras. Jornadas sobre la politica en Buenos Aires en el siglo XX. La Plata: CISH, Facultad de Humanidades y Ciencias de la Educación.

3 Véase, Amaral, S. y Plotkin, M. (comp.) (1993), Perón, del exilio al poder. Buenos Aires: Cántaros Editores.

4 Véase, García Bossio, H. (2014). ¿Qué nos hace más Nación? Desafíos del desarrollismo frondicista-frigerista. Buenos Aires: EdUNLa cooperativa.

5 Decreto (S) 9880/58, 5 de marzo de 2013, Boletín Oficial de la República Argentina. Recuperado de: http://www.eld ial.com.ar/nuevo/boletin/2013/BO130305.pdf. Este Decreto, junto con otros de carácter secreto y reservado, fueron publicados en el Boletín Oficial del mes de marzo de 2013, acorde a lo establecido por el Decreto 2103/2012, donde se indicó la desclasificación de los mismos.

6 Decreto $N^{\circ}$ 15385, 13-jun-1944, art. 1. Recuperado de: http://www.infoleg.gov.ar/infolegInternet/anexos/30000-34 999/31918/norma.htm.

7 Archivo DIPPBA, Panfleto de la Unión Ferroviaria, Mesa B, Factor Gremial, Carpeta 4, Legajo 2, 8 de octubre de 1958, folio 68.

8 Rapan guardas de ferrocarriles (3 de diciembre de 1958), La Verdad, portada.

9 Rascio, A. (1956). El Comunismo en la Provincia. Su desarrollo, sistema de trabajo. El porvenir de esta ideología. Soluciones, Anexo de la revista de Policía, Provincia de Buenos Aires (s/p). La Plata.

$10 \mathrm{La}$ dependencia policial de inteligencia bonaerense fue creada en 1956 con el nombre de Central de Inteligencia y disuelta en 1998, en el contexto de una reforma de la policía bonaerense. Si bien a lo largo de su historia fue variando en nominaciones y jerarquías, desde su creación, como mencionan desde la Comisión Provincial por la Memoria, "la DIPPBA tuvo una constante tarea vinculada a la producción de información y la acción de inteligencia, elemento que la convirtió en un eslabón fundamental del terrorismo de Estado en la provincia de Buenos Aires”. Recuperado de: ht tp://www.comisionporlamemoria.org/la-dippba/.

12 En 1974 se desactiva la policía ferroviaria y se crea la Superintendencia de la Policía del Tráfico Ferroviario mediante la Ley No 20.952, y la seguridad pasa a manos de la Policía Federal. Fuente: http://servicios.infoleg.gob.ar/infolegIntern et/anexos/180000-184999/182701/norma.htm

13 Entrevista a Floreal Volini, Junín, 21 de septiembre de 2019.

14 Entrevista a Ismael Tornello, Junín, 18 de septiembre de 2019. Ismael fue detenido en 1976 durante la última dictadura cívico militar, estuvo a disposición del Poder Ejecutivo un año y medio en la cárcel de Mercedes, provincia de Buenos Aires.

15 Para profundizar en los lazos identitarios que se generaron en torno al mundo del ferrocarril, véase, Baladoni L. (2011). La familia ferroviaria a principios del siglo XX. Bienestar y lealtades de hierro en el Ferrocarril Central Argentino. En D. Dicósimo y S. Simonassi (Ed.), Trabajadores y empresarios en la Argentina del siglo XX: indagaciones desde la historia social (pp. 143-157). Rosario: Prohistoria Ediciones. Para el caso de Junín, Sagastume, A. (2018). Familias ferroviarias de mediados del siglo XX en Junín, provincia de Buenos Aires. En, G. Quinteros y M. Cowen, (comp.), Familias de ayer y hoy: Las sociedades ibéricas y el Río de La Plata (pp. 309-329). La Plata: FaHCE, UNLP.

16 Decreto Nº 2628 (B.O 16-III/60), Anales de la Legislatura Argentina, La Ley: Buenos Aires 1961, pág. 367.

17 Decreto No 2639 (B.O 16-III/60), Anales de la Legislatura Argentina La Ley: Buenos Aires 1961, pp. 367-368.

18 Este caso, como la situación concerniente al Frigorífico Nacional Lisandro de la Torre fue llevado a la Organización Internacional del Trabajo (OIT). La respuesta del gobierno ante el informe que envía la OIT fue declarada parcial por la misma entidad internacional. Entre otros aspectos, se advertía desde la OIT que los trabajadores movilizados habían sido objeto de persecución y se les había infligido penas al amparo de una legislación asimilable a un régimen legal de excepción. Fuente: http://www.ilo.org/dyn/normlex/es/f?p=NORMLEXPUB:50002:0::NO::P50002_CO MPLAINT_TEXT_ID:2898350 